\title{
28 Research Square \\ Surgical excision of complex lipoma from the foot: a case report
}

\section{Akram Uddin}

Northamptonshire Healthcare NHS Foundation Trust \& Essex Partnership University NHS Foundation

Trust https://orcid.org/0000-0001-7780-1760

\section{George Flanagan}

Northamptonshire Healthcare NHS Foundation Trust https://orcid.org/0000-0002-5166-7580

lan Reilly ( $\sim$ ian.reilly@nhs.net)

Northamptonshire Healthcare NHS Foundation Trust1 https://orcid.org/0000-0002-2786-5739

\section{Case Report}

Keywords: Lipoma, liposarcoma, benign tumour, soft tissue tumour, malignant tumour, core needle biopsy, fine needle aspiration

Posted Date: December 1st, 2020

DOI: https://doi.org/10.21203/rs.3.rs-99671/v4

License: (1) (1) This work is licensed under a Creative Commons Attribution 4.0 International License. Read Full License 


\section{Abstract}

Background: Soft tissue malignant tumours of the foot and ankle are rare. Diagnostic imaging and interventional biopsy are vital to establish the nature and grading of a suspicious tumour prior to surgical intervention. The purpose of the study is to provide an account on how a symptomatic mass to the plantar aspect of the foot warranted a referral to a sarcoma centre, highlighting the importance of having urgent access to diagnostic imaging and a pathway to refer suspected cases to specialist centres.

Method: A single patient with a symptomatic soft tissue tumour of the plantar foot was referred from our service to the regional sarcoma centre. It was considered to be benign and therefore open surgical resection was performed under local anaesthesia by our team, and the lesion sent for histopathological examination.

Results: Histopathological analysis identified the excised mass as a lipoma to show no atypia or necrosis and mature adipose tissue with fibrous bands. At 2 years postoperatively there was no recurrence and the patient presented an asymptomatic foot. Favourable patient reported outcomes measures were observed.

Conclusion: United Kingdom (UK) Guidelines suggest that all soft tissue masses of suspicious nature, greater than $50 \mathrm{~mm}$, deep seated irrespective of size, or fast growing should be referred to a sarcoma unit prior to surgical management. European guidance identifies a threshold of $15 \mathrm{~mm}$ for a mass in the foot. Patients presenting with red flag symptoms irrespective of size of mass should be referred to a sarcoma centre. Advanced imaging and multidisciplinary input to enable appropriate surgical planning is recommended for these soft tissue tumours that present to the foot and ankle surgeon.

Level of evidence: $\vee$ case study.

\section{Introduction}

Lipoma is the most common form of soft tissue benign tumour that occurs as a result of hypertrophy of adipose cells $[1,2,3,4,5]$. The World Health Organisation (WHO) categorises lipomas, angiolipomas and liposarcomas as adipocytic tumours [6]. Adipocytic masses are considered to be the largest single group of mesenchymal tumours [7]. These benign or malignant lipomatous tumours are common mesenchymal neoplasms of lipogenic differentiation [1, 8]. An atypical lipomatous tumour is considered synonymous with a well-differentiated liposarcoma and it is identified as the most common soft tissue sarcoma in adults [9]. In adults, liposarcomas are the second most common malignancy of soft tissues usually involving the lower extremity and is very rare in the adult foot $[8,10,11]$. Liposarcomas are classified into sub-types: well differentiated (atypical), myxoid, pleomorphic, round cell and differentiated $[12,13,14]$. Primary and metastatic tumours in the foot and ankle have been reported to be rare [15]. In such cases, genetic, environmental, irradiation, viral and immune deficiencies have been found associated with the development of these malignant neoplasms [16]. 
Lipomas can occur at any age and are the most common soft tissue tumour found in humans, accounting for $50 \%$ of all benign soft tissue tumours $[3,17]$. They can present anywhere in the body where adipose tissue presents [18]. Lipomas are four times more prevalent in males than females, often occurring in obese subjects between the ages of $40-60[2,3,19,20]$. Paediatric lipomas have been reported as early as 18 months of age [21]. Familial lipomas range from single to multiple lesions due to autosomal dominant inheritance [19]. Single presentation occurs more commonly in the female population and multiple lipomas more commonly affect males [2]. Intramuscular lipomas are rare and characterized due to its nature of infiltrating into muscle fibres [22]. Cardiac lipomas constitute $8.4 \%$ of primary heart and pericardial tumours and intracavitary lesions can cause dyspnoea, syncope, atrial fibrillation and angina [2, 23, 24]. Intracranial lipomas constitute $0.1-0.5 \%$ of all primary brain tumours [2]. Intraosseous lipoma is a rare subset of osteolipoma seen in the calcaneus representing $0.1 \%$ of all skeletal tumours and often incidentally discovered during radiological imaging $[25,26,27]$. The incidence of benign lipoma to the sole of the foot is uncommon $[21,28,29]$.

The aetiology and pathophysiology of lipoma is unknown $[2,3,20]$. Lipomas grow slowly within the subcutaneous region $[4,19]$. They classically present as asymptomatic soft, subcutaneous and oval masses that are palpable and mobile [2, 3, 4]. Subcutaneous lipomas are usually thin encapsulated with lobular patterns and deeper-seated lipomas have an irregular configuration $[4,20]$.

The non-surgical options for lipomas include corticosteroids, phosphatidylcholine and sodium deoxycholate injections, all aiming to achieve chemical lipolysis or atrophy of the lesion [4, 30, 31]. Extracorporeal acoustic wave therapy [32], laser lipolysis [33] and high intensity focused ultrasound have also been identified as safe and well tolerated treatments [34]. Statin therapy is identified to induce apoptosis in lipoma cells [35]. Open surgical excision is the most common intervention with recurrence rate reported to be less than 5\% [4] contrary to intramuscular lipomas with recurrence reported as high as $50-80 \%$ [22]. Endoscopic resection of subcutaneous lipoma has been described and is reserved for benign tumours [36]. The recurrence rate for benign soft tissue tumours is generally low after marginal resection in contrast to soft tissue sarcomas where mortality rate is significantly high [37].

Benign and often asymptomatic, lipomas require differentiation from other malignant tumours [1, 2]. Accurate diagnosis is vital when managing soft tissue tumours and this is achieved in combination with clinical, radiological and histological examinations [38, 39]. Detailed knowledge of incidence and distribution patterns of foot and ankle tumours will provide a systematic approach in assessment, diagnostic investigations and treatment [40]. Deep seated tumours $>5 \mathrm{~cm}$ are identified to be more likely to be sarcomas [1], contrary to small superficial masses $<30 \mathrm{~mm}$ having been reported to be malignant tumours from the hand and foot [41]. In the human foot and hand a mass less than $15 \mathrm{~mm}$ is considered small whereas $<50 \mathrm{~mm}$ is generally considered small in the remaining anatomy. [11].

Diagnostic imaging may not be fully conclusive for a benign lipoma. Diagnostic uncertainty occurs when the features are not typical of a lipoma and differentiation of lipoma variants from liposarcoma is required, therefore necessitating resection for a definitive histological diagnosis [28]. The appearance of 
lipomatous tumours on MRI reflects the degree of differentiation [8]. MRI represents the modality of choice to investigate the nature of the soft tissue tumours and is helpful to the surgeon when planning excision [18, 42]. Biopsy techniques include fine needle aspiration (FNA), core needle biopsy and incisional biopsy and these procedures are important for diagnostic, staging and surgery planning $[11,38$, $43,44]$. Open excisional biopsy remains the gold standard for histologic diagnosis of lipoma [20].

\section{Case Report}

A 49-year-old female patient was referred to podiatric surgery by her General Practitioner (GP) for a symptomatic mass on the plantar aspect of the left foot. The patient was American Society of Anaesthesiologists [45] (ASA) physical status grade II. The patient's medical history included sickle cell trait (HbAS), malaria, ocular hypertension, glaucoma, hypertension and she was on repeat pharmacotherapy of amitriptyline, bimatoprost/timolol, doxazosin and desunin. The patient was a nonsmoker and reported nil consumption of alcohol. The patient reported an allergy (Type I) to proguanil and chloroquine phosphate. There was no other current or history of previous soft tissue mass or family history. There was no history of recent foreign travel, insect or animal bite or any lower limb injury. The patients' occupational role was in acute nursing care.

The (patient reported) duration of the mass was two months with gradual increase in size. The GP suspected a plantar fibroma and requested an ultrasound scan (USS). The Radiologist's report of the USS dismissed a plantar fibroma and advised 'further assessment' and a magnetic resonance image (MRI) was performed (see figs 1, 2 and 3 ).

For the MRI Report - see table.

\footnotetext{
Clinical Information:

No contra indications; left foot distal medial arch large soft tissue mass [prox 1st MTPJ] Previous US NGH, recommends MRI investigation.

Report:

MRI left foot (as per protocol).

Comparison is made with a previous ultrasound scan from 25/10/2017. The clinically palpable lump in the plantar aspect at the level of the first MTP joint corresponds to a lobulated soft tissue mass which returns high T1 signal and suppresses uniformly on the fat suppression sequences. The lesion involves the subcutaneous tissue and extends into the muscular compartments and superiorly extends into the first

interspace. The lesion approximately measures $80 \times 15 \mathrm{~mm}$ in the maximum axial dimension and $23 \mathrm{~mm}$ in the anterior posterior dimension. Posterior to this there is a further discrete lesion and the level of the tarsal bones within the subcutaneous tissue measuring and $9 \times 9 \mathrm{~mm}$. The underlying bones are normal.

Conclusion:

Features are in keeping with a complex lipoma but underlying sarcomatous change cannot be excluded given the size of the lesion.
}

Table: MRI report

On clinical examination, a single atypical non-uniform mass was located sub-dermally to the plantar aspect of the left foot. The mass extended from the plantar aspect of the medial cuneiform, extending plantar distally to the $1^{\text {st }}$ ray and proximal to the $1^{\text {st }}$ metatarso-phalangeal joint. Clinically the mass 
measured $60 \mathrm{~mm} \times 25 \mathrm{~mm}$ with protrusion expansion of $8 \mathrm{~mm}$. There were no trophic changes, skin tone and cutaneous colouration was unvarying.

There was no temperature difference of clinical significance. This was examined with an infrared thermographic scanner comparing the mass site to the proximal lower limb and comparison to the opposite limb. The foot displayed no structural abnormality or asymmetry. The mass was non-pulsatile and Doppler examination identified no audible vascular echo or on mass pressure and release. All three pedal arteries (posterior tibial, dorsalis pedis and peroneal) were triphasic on handheld Doppler. Venous examination identified no abnormality. There were no clinical signs or symptoms of lymphangitis or lymphadenitis. The patient displayed no sensorimotor or autonomic neuropathy to both limbs. Sensory testing identified normal cutaneous innervation to each dermatome areas. Motor assessment of the intrinsic and extrinsic foot muscles demonstrated satisfactory function and resistance. Proprioception examination was unremarkable. Cutaneous colouration, hydration, tone and dermal elasticity were symmetrical. The contralateral foot was asymptomatic and defined no features of soft tissue mass occurrence.

The patient attended systemically well, reported good well-being and there were no reported red flag symptoms. There was no allodynia and the patient allowed the foot to be examined. Symptoms were described as a deep dull aching sensation rated 9/10 on the Visual Analogue Pain Scale (VAS). Pain was worst when weight bearing although rest pain was also present. Pain responded to over the counter paracetamol. The mass on examination was dense and appeared fixed in volume with no dispersity. When weight bearing the patient displayed plantar ground contact however expressed discomfort and compensated with varus stance. The patient reported footwear was becoming uncomfortable due to notable mass expansion.

\section{Referral to Sarcoma Service}

The National Institute for Health and Care Excellence (NICE) reports sarcomas are rare, but to avoid delay in diagnosis patients with suspected sarcomas need to be recognised early and quickly referred to the sarcoma service [46]. The NICE [47] guidance recommends an urgent ultrasound scan within 2 weeks to assess for soft tissue sarcoma in adults with an unexplained lump that is increasing in size. The guidance also highlights if the USS findings are suggestive of a soft tissue sarcoma, uncertain and clinical concern persists to consider a suspected cancer pathway referral within 2 weeks for an adult. It is essential to assess the continued support for the patient whilst waiting for the referral appointment and the patient given opportunity to express concerns or ask questions [47].

The Northamptonshire NHS department of podiatric surgery run a morbidity and mortality (M\&M) meeting every month. The meeting involves discussing cases that may warrant further diagnostics, referral or support from primary and secondary centres. Furthermore, complex cases requiring additional perioperative planning or equipment needs are agreed upon. Upon reviewing this case, diagnostic USS and MRI scans, it was decided to refer the patient to the regional sarcoma unit prior to performing 
surgical resection. This decision was made following our local Sarcoma Service guidelines and NICE [46, 47] recommendations (fig. 4).

The patient was well informed of the outcome following the M\&M meeting with a face to face consultation and she agreed to be referred to the local sarcoma service. This consultation was important as it made the patient feel they were part of the decision-making process and an opportunity to give support and a sense of understanding all diagnostic options and safety were core to our treatment planning. After the patient attended the sarcoma unit, written confirmation was received from the service confirming the lesion to be urgently excised for histopathological examination and requested that our team perform the surgery. The patient was booked for preoperative assessment and surgical planning. Routine preoperative blood tests requested were within normal physiological range.

\section{Surgical Procedure}

A local anaesthetic (ropivacaine HCL $0.75 \%$ ) ankle block was performed under ultrasound guidance. Ropivacaine $\mathrm{HCL}$ is identified to have prolonged duration of anaesthesia, profound sensory with less motor blockade and reduced risk of cardiotoxicity $[49,50]$.

The foot was prepped in standard fashion and the procedure undertaken with an ankle tourniquet with patient positioned supine. A curvilinear lazy " $\mathrm{S}$ " incision of the skin was performed on the plantar aspect of the foot over the mass respecting cutaneous angiosomes. The incision choice was for appropriate surgical exposure and to avoid scar contracture. The incision was deepened, and vessels encountered were cauterised with bipolar diathermy. Blunt dissection was performed to separate the subcutaneous layer until the body of the mass was identified.

A dense uniform mass was identified on subcutaneous reflection with unvarying colouration with no direct vascular supply (figs 5-6). The mass was invasive and enveloped the medial plantar nerve requiring blunt separation (fig 5 ) and once resected whole it was sent for histopathological analysis (fig 7). The evacuated site was examined to ensure no remaining tissue of the mass was present and once satisfied copious irrigation was performed with saline. The deep fascia closure was performed to reduce evacuated mass space that was a potential for seroma or haematoma formation. Deep fascia layer closure was achieved in layers with interrupted 4.0 Vicryl ${ }^{\circledR}$ sutures. An external vacuum drain was not deemed necessary based on our judgement. Skin closure was completed with simple interrupted suture technique using 4.0 Prolene® (fig 8). Tourniquet deflation was performed to appreciate digital cutaneous reperfusion and to ensure inadvertent vascular damage had not occurred. A postoperative standard sterile dressing was applied. The patient was advised to be non-weight bearing with crutches and supplied with postoperative analgesia and instructions as service protocol.

The dressing was changed at 14 days, as per our routine, plantar sutures were removed at 28 days. The histopathology report noted: 
A piece of multilobular fatty tissue $60 \times 30 \times 20$ millimetres

On slicing specimen appears to consist of unremarkable fat

Sections show mature adipose tissue with mature fibrous bands within

No atypia necrosis or mitosis is seen - lipoma.

A seroma noted at week 4 was treated empirically with flucloxacillin 500mg QDS and metronidazole $400 \mathrm{mg} \mathrm{BD}$, both for 7 days (fig 9). A deep wound swab demonstrated normal skin flora only and the wound was fully healed six weeks. Patient follow up was undertaken at 2 weeks, 4 weeks, 6 months and 24 months post operatively.

\section{Results}

Clinically no sign of recurrence has been documented to date. Patient reported outcome measures were determined pre-operatively and at 24 months postoperatively. A patient satisfaction questionnaire was completed; at 24 months postoperative the patient noted their foot was 'much better' with no discomfort. A 10-point visual analogue scale was use to rate pain, this reduced from $9 / 10$ preoperatively to $0 / 10$ at 24 months post intervention. The Manchester Oxford Foot Questionnaire [51] (MOXFQ) showed a significant reduction in all 3 domains. In the walking / standing (WS) domain the average pre-treatment score was 39 , the post treatment score reduced to 14 . For social interaction (SI) scores reduced from 56 to 0 and in the pain $(P)$ category 30 and 0 respectively.

\section{Discussion}

Tumours of the foot and ankle account for $4-5 \%$ of all musculoskeletal tumours [52]. The majority of the soft tissue tumours of the foot and ankle are uncommon and benign [37, 43]. Sarcomas of the lower extremity are uncommon and believed to be less malignant than those that arise in other sites [53]. The prognosis of foot malignant tumours and metastatic spread is no different from any other anatomical location but considered less in chondrosarcoma [11]. Lipomas account for $50 \%$ and are most benign soft tissue tumours $[1,4,5,17,19]$. The occurrence of lipoma to the plantar aspect of the foot is rare [28]. It is important to differentiate the benign lesion from an aggressive benign or malignant tumour [2,39]. The infrequency of soft tissue sarcoma may lead to a lack of consideration when soft tissue masses present [54]. Public Health England National Cancer Registration and Analysis Service (NCRAS) reported approximately $10 \%$ of all soft tissue sarcoma cases are liposarcomas in England [55]. Unplanned excision of a sarcoma of the foot can lead to worse oncological, failed limb salvage, recurrence, metastasis and death [54]. Although less common, malignant tumours of the lower extremity remain a threat and must be studied by diagnostic imaging and biopsies performed as necessary [53]. Histopathology, however, remains the gold standard in the diagnosis of lipoma [20]. A lesion lacking features of a benign entity should be considered malignant until proven otherwise [43]. 
When assessing tumours of the foot, plain radiograph shows soft tissue masses in the form of increased density with or without calcification or osseous involvement $[10,11,39]$. Radiographs may also demonstrate expansile fatty masses or effacement of usual fat planes [56] but none were required for this case.

USS evaluation of soft tissue lesions is useful in the initial triaging of soft tissue masses [43]. It is a useful diagnostic tool of superficial lipomas with good sensitivity and even better specificity and should remain the first line imaging investigation [57]. Furthermore, it helps determine the size, shape and outlines of the expansile tissue process and internal structure and homogeneity [17]. USS examination, however, requires sufficient operator and radiologist expertise to assist with diagnosis [56]. Furthermore, the mass is only appreciated in one plane and deeper structures are not well appreciated due to reduced resolution. Rahimi et al. (2017) conducted a systematic review on the diagnostic accuracy of ultrasonography for lipomas. The sensitivity and specificity were $86.87 \%$ and $95.95 \%$ respectively therefore supporting this imaging modality to be the first line imaging investigation.

The USS report of this case study confirmed a mass with mixed reflectivity that was predominantly echogenic measuring $16 \mathrm{~mm} \times 13 \mathrm{~mm} \times 12 \mathrm{~mm}$. On clinical correlation and history taking, the mass had rapidly expanded since the USS was performed. The report confirmed the mass to be located within the superficial soft tissues with extension of the mass into the deeper plantar soft tissue layers which were not visible on USS. Therefore, as an atypical lipoma was suggested as a probable diagnosis, we requested an urgent MRI.

MRI evaluation should follow on from US examination where there is reasonable chance of malignancy [43]. MRI should comprise at least T1, T2 and T1 fat-saturated sequences [11]. Advanced techniques such as spectroscopy, perfusion and diffusion weighted imaging may provide enhanced soft tissue characterisation [43]. Lipomatous tumours can be characterized with MRI because of their predominant T1 signal intensity that is similar to subcutaneous fat on all pulse sequences [8]. Intravenous contrast allows for distinction between cystic lesions and dense masses [56]. On T1 weighted images lipomas demonstrate high signal uniform intensity with low signal intensity appreciated on T2 weighted images $[4,5]$. However, some lipomas contain mesenchymal non-fatty elements and therefore differ from this typical homogeneous MRI appearance [58]. On Short-Tau Inversion Recovery (STIR images), the fat signal of lipomas is nulled [8]. Furthermore, MRI allows cross sectional nodular components to be appreciated and large size lesions with septations thicker than $2 \mathrm{~mm}$ direct towards liposarcoma over lipoma [39]. However, some lipomas can contain septa thicker than expected therefore this parameter although useful is less reliable [58].

Our request for MRI was to appreciate the nature of the mass and tissue matrix composition for diagnostic purposes and exact anatomical location and establish the extent of neighbouring anatomy involvement to assist with surgical planning. If the patient was contraindicated for MRI, we would have requested a Computer Tomography (CT) scan with contrast. Contrast enhanced CT scans can help 
distinguish masses from surrounding soft tissues and reveal vascular involvement [56]. On CT scans lipomas present as homogeneous hypo attenuated lesions [4].

Open or image guided biopsies are recommended if a soft tissue mass of the foot or ankle cannot be further distinguished by diagnostic imaging [16]. Percutaneous needle biopsies are extremely effective and safe in the diagnosis of soft tissue masses [59]. The biopsy should be performed in a sarcoma centre, involving multidisciplinary input including the oncologic surgeon $[11,43,60]$. This is due to the technical considerations that are required when taking a biopsy for histological diagnosis and without further spreading of the tumour $[38,60]$.

The referral for biopsy is indicated when a superficial lesion is $>50 \mathrm{~mm}$, any deep lesion regardless of size and in atypical presentation cases $[17,43]$. In the human foot the threshold is reported $15 \mathrm{~mm}$ and $50 \mathrm{~mm}$ for the rest of the body [11]. Fine needle aspiration (FNA) has the advantage of enabling the aspiration of various parts of the same tumour which is important in large heterogeneous neoplasms [61]. FNA allows aspiration of material for pathological examination of the cells [60]. Immediate evaluation of FNA specimen is advantageous due to its fast and simple technique [62]. Incisional biopsies carry a risk of haematoma which may delay treatment as well as increasing the risk of local dissemination of the tumour [60]. Core needle biopsy (CNB) is a technique to achieve histological diagnosis but can also help grade a tumour and allows immunohistochemical or molecular analysis [38]. Welker et al (2000) analysed core needle biopsies in 155 patients with soft tissue sarcoma and reported positive predictive values of $100 \%$ and negative value of $82 \%$. The sensitivity of this technique was reported to be $81.8 \%$ and specificity $100 \%$ therefore this technique can be considered to be extremely reliable for the diagnosis of soft tissue tumours. A single biopsy was adequate for 142 masses with 7 requiring multiple biopsies. However, 12 masses required open biopsy due to failure to obtain adequate diagnosis. Whether this was due to the size of the mass or anatomical location, patient or operator factors as well as failure of intraprocedural imaging is unclear.

Kilpatrick et al [63] conducted FNA on 140 patients for the primary diagnosis of sarcoma. All needle placements were assisted by ultrasound imaging or CT-guided and no complications were reported and no local recurrences in the FNA track. Cardoso et al [61] study validated the diagnostic accuracy of FNA in 36 soft tissue masses. The diagnostic accuracy for soft tissue lesions was $94.7 \%$ with all patients reporting no complications. The limitation to FNA reported in this study is if insufficient sample is obtained a diagnosis may not be made. Kilpatrick et al [63] did not support FNA to distinguish lipoma or lipoma-like liposarcoma as all of these masses may contain areas of normal adipose tissue and propose incisional or excisional biopsy.

Both CNB and FNA are less invasive and cause fewer complications [62]. The advantage of CNB is that the cylindrical tissue allows the pathologist to examine the tumour architecture and interrelation of its cells which is not achievable with FNA as the aspiration is not structurally connected [59]. CNB has the higher diagnostic accuracy than FNA in all aspects including the nature of the tumour, establishing the histologic type and grade and achieving a specific diagnosis [62]. 
Konoshita et al [37] reviewed 83 cases of tumours of the foot. 47 of these cases were soft tissue tumours with a male to female ratio of 14:33. All cases underwent marginal resection and reported no recurrence for benign lesions in contrast to all patients with soft tissue sarcoma dying after surgery. The study reported most soft tissue masses occurring to the mid-area and this could have been better reported on by specifying areas of location such as specific joints and soft tissue compartments of the foot. Furthermore, there was no grading or classification of these tumours that may help correlate the prognosis outcomes. Toepfer et al [64] similarly identified the incidence and distribution of foot and ankle tumours. Out of 7487 tumours, 147 (36\%) soft tissue tumours were identified, 104 of which were benign and 43 malignant. The study used an anatomical classification system with most benign tumours occurring at the talo-crural joint and malignant tumours occurring at the mid-foot.

Chou et al [15] retrospectively reviewed 153 tumours of the foot \& ankle identifying overall incidence of 93 benign cases $(60.8 \%)$ and 60 malignant cases (39.2\%) with 2 cases of metastases reported. $50 \%$ of malignant tumours were able to be treated with limb-sparing procedures therefore equally highlighting the amputation rate. The appropriate management therefore has a significant impact on a patient's functional outcome, and this must be considered by the surgeon.

The function of the foot is important and must be considered when resecting tumours and surgery must be performed to avoid nerve or muscle [21]. The functional outcome in limb salvage surgery for soft tissue tumours was prospectively evaluated in 36 patients using the modified Enneking functional rating scale [65]. This study reported on the Musculoskeletal Tumour Society (MSTS) functional rating scale with $85 \%$ of patients reporting good to excellent outcomes at 12 months postoperatively. The study highlighted the importance to place emphasis on functional issues as well as managing the tumour. Latt et al [54] similarly reported using the MSTS scale but also conducted postoperative functional measures using the Toronto Extremity Salvage Score (TESS). The findings from this study are difficult to compare to others as patients were treated in other centres initially by unplanned excision which led to worse oncological outcomes. Our case study although assessed the functional outcome with the MOXFQ cannot be compared to functional outcome scores from these studies although the TESS is a patient completed tool.

Multiple and large subcutaneous lipomas may cause challenges in surgical planning and access [2]. It is considered when surgically soft tissue tumours of the foot and ankle may require free muscle flap reconstruction and split thickness skin grafts [65]. The functional demands of the foot and related structures, the limitations of soft tissue coverage as well as underlying vital anatomy must be taken into consideration before planning limb salvage surgery [65]. The plantar incision performed for this case study ensured cutaneous angiosome perfusion was not affected, anatomical exposure and visualisation of key neurovascular structures was achievable allowing meticulous surgical resection. The functional demands of the foot were considered when planning the surgery and intraoperatively no inadvertent complication occurred. The plantar approach also allowed the intrinsic anatomy of the foot to be visualised and adequate resection to be performed. 
Transudate and ultimately exudative accumulation is a risk factor following surgery, in particular when excising space occupying lesions. In this case the benefit of a closed suction drain was deemed to be of little benefit, however we highlighted the development of seroma following surgery. Studies have highlighted the benefits of post-surgical wound drainage to reduce post-operative sequelae [66]. The use of drains, even for marginal space occupying lesions, should be considered.

Su et al [5] reported on marginal combined with wide excision of intramuscular infiltrating lipoma in 8 patients who were all female. At an average period of 40 months follow up, no recurrence was reported. Marginal excision was reported to have been performed around the well encapsulated border and the infiltration area was widely excised with a muscular cuff to achieve clear margin. The level of marginal excision was not clearly defined in this study or the ratio to excision based on mass size.

\section{Conclusion}

Although the incidence of non-benign lesions to be found in the human foot and ankle is low, not every atypical mass presentation should be treated by simple resection without wider consideration. Surgeons should additionally interpret diagnostic imaging themselves rather than relying on a Radiologist's report alone. MRI should be the imaging modality of choice and in cases where it is contraindicated, an alternative modality such as contrast CT scan should be considered. An X-ray should be considered to rule out osseous involvement. If a mass is of suspicious nature, deep seated, greater than $15 \mathrm{~mm}$, rapidly expanding and there are red flag symptoms - the case must be referred to the regional sarcoma service.

To meet the recommendations of NICE $[46,47]$, every surgery unit should ensure that they follow set pathways for referral and diagnosis for patients with suspected sarcoma. Once a decision to refer has been made, this must be done within one working day [47]. Confidentiality, patient support, good communication with information on possible diagnosis in accordance with their wishes must be given [47].

Furthermore, M\&M meetings jointly attended by Podiatric Surgeons, Orthopaedic Surgeons, Podiatrists and Radiologists should be welcomed for clinical governance, multidisciplinary working, reflective and safe surgical practice. Clinicians should be mindful of the ethos and principles developed by the 'Getting It Right First Time' (GIRFT) programme when considering diagnosis and treatment of such tumours.

At 24 months postoperative stages the patient was reviewed and reported outcome measures (MOXFQ \& PSQ10) were recorded. To date there is no recurrence of lipoma. The patient is asymptomatic and returned to their activities of daily living. Subsequently the patient has been discharged from our surgical unit.

\section{Declarations}

Acknowledgements 
The authors thank Jane Cooper, Lead Librarian at Northampton General Hospital Post Graduate Centre for her help with the collection of reference papers. We also thank our patient for granting permission to use her case for publication.

\section{Declarations}

This research did not receive any grant from funding agencies in the public, commercial, or not-for-profit sectors. All authors have no competing interests to declare. Organisation ethical approval was not required but patient consent for publishing of images was obtained. All authors made substantial contributions to the work enclosed.

\section{References}


[1] A. Azam, S. Rajagopalan and W. A. Niezywinski, "A Rapidly Expanding Massive Lipoma of the Toe," The Journal of Foot \& Ankle Surgery, vol. 46, no. 6, pp. 499-501, 2007.

[2] R. Sitarz, M. Skierrucha, M. Jazienicki, A. Kurylcio, R. Wierzbicki, R. Maciejewski and W. P. Polkowski, "Lipomas - a health condition that cannot be ignored," Family Medicine \& Primary Care Review, vol. 18, no. 4, pp. 473-476, 2016.

[3] M. Swarnkar and S. C. Jain, "Web Space Lipoma Causing Separation of Toes - A Rare Case Report with Review of Literature," Journal of Krishna Institute of Medical Sciences University, vol. 6, no. 2, pp. 107-109, 2017.

[4] A. T. Derin and N. Yaprak, "Lipomas: Review and Evaluation of the Literature," Clinics in Surgery, vol. 2, no. 1615, pp. 1-2, 2015.

[5] C.-H. Su, J.-K. Hung and I.-L. Chang, "Surgical Treatment of Intramuscular, Infiltrating Lipoma," Int Surg, vol. 96, pp. 56-59, 2011.

[6] C. D. Fletcher, J. A. Bridge, P. C. Hogendoorn and F. Mertens, WHO Classification of Tumours of Soft Tissue and Bone. Pathology and Genetics of Tumours of Soft Tissue and Bone., Lyon: IARC Press, 2013.

[7] J. C. Vilanova, WHO Classification of Soft Tissue Tumors. In: Vanhoenacker F., Parizel P., Gielen J. (eds) Imaging of Soft Tissue Tumors, Springer, Cham, 2017.

[8] A. Drevelegas, M. Pilavaki and D. Chourmouzi, "Lipomatous tumours of soft tissue: MR appearance with histological correlation," European Journal of Radiology, vol. 50, pp. 257-267, 2004.

[9] A. Corvino, G. Riva, M. Sensini, M. Garzaro and G. Perorari, "Liposarcoma of the hypopharynx: a systematic review of the lioterature," Journal of Health and Social Sciences, vol. 1, no. 1, pp. 5766, 2016.

[10] S. Kure, W.-X. Peng, M. Kudo, M. Matsubara, T. Tsunoda and Z. Naito, "A rare case of myxoid liposarcoma of the adult foot diagnosed using fine needle aspiration cytology (FNAC)," Pathology and Laboratory Medicine International, vol. 7, pp. 1-5, 2015.

[11] E. Mascard, N. Gasper, L. Brugières, C. Glorion, S. Pannier and A. Gomez-Brouchet, "Malignant tumours of the foot and ankle," EFORT Open Rev, vol. 2, no. 5, pp. 261-271, 2017.

[12] M. Koczkowska, B. S. Lipska-Ziętkiewicz, M. Iliszko, J. Ryś, M. Miettinen, J. Lasota, W. Biernat, A. Harazin-Lechowska, A. Kruczak and J. Limon, "Application of high-resolution genomic profiling in the differential diagnosis of liposarcoma," Molecular Cytogenetics, vol. 10, no. 7, pp. $1-9,2017$.

[13] J. Klijanienko, J. M. Caillaud and R. Lagacé, "Fine-needle aspiration in liposarcoma: cytohistologic correlative study including well-differentiated, myxoid, and pleomorphic variants.," Diagnostic Cytopathology, vol. 30, no. 5, pp. 307-312, 2004.

[14] A. T. Lee, K. Thway, P. H. Huang and R. L. Jones, "Clinical and Molecular Spectrum of Liposarcoma," J Clin Oncol, vol. 36, no. 2, pp. 151-159, 2018.

[15] L. B. Chou, Y. Y. Ho and M. M. Malawer, "Tumors of the foot and ankle: experience with 153 cases," Foot Ankle Int, vol. 30, no. 9, pp. 836-841, 2009.

[16] A. Toepfer, "Tumors of the foot and ankle - A review of the principles of diagnostics and treatment," Fuß \& Sprunggelenk, vol. 15, no. 2, pp. 82-96, 2017.

[17] F. Loubignac, C. Bourtoul and F. Chapel, "Myxoid liposarcoma: a rare soft-tissue tumor with a misleading benign appearance," World J Surg Onc, vol. 7, no. 42, 2017. 
[18] K. Y. Fan and T. H. Lui, "Lipoma of the sinus tarsi," BMJ Case Rep, 2013.

[19] V. Curca, V. Culiuc and F. Bzovii, "Atypical giant lipomas," Curierul Medical, vol. 57, no. 2, pp. 102-105, 2014.

[20] R. Kaur, S. Kler and A. Bhullar, "Intraoral lipoma: report of 3 cases.," Dental Research Journal, vol. 8, no. 1, pp. 48-51, 2011.

[21] K. Yasumura, T. Satake, M. Shibuya, M. Ogawa, S. Kobayashi, T. Mikami and J. Maegawa, "A case of recurrent lipoma in the sole with long-term follow-up," JPRAS, vol. 8, pp. 19-22, 2016.

[22] H. H. Han, Y. J. Choi, B. F. Seo, S. H. Moon, D. Y. Oh, S. T. Ahn and J. W. Rhie, "Treatment for intramuscular lipoma frequently confused with sarcoma: a 6-year restrospective study and literature review.," Biomed Res Int, 2014.

[23] P. Korantzopoulos, D. Patsouras and E. Kountouris, "Lipoma of the Interatrial Septum in a Patient With Chronic Atrial Fibrillation: A Case Report," Angiology, vol. 57, no. 4, pp. 513-516, 2006.

[24] I. Ismail, K. Al-Khafaji, S. Aggarwal and M. Mutyala, "Cardiac lipoma," Journal of Community Hospital Internal Medicine Perspectives, vol. 5, no. 5, 2015.

[25] A. Sani, M. Y. Bajuri and M. H. Shukur, "Intraosseous lipoma of the calcaneus: The nonstereotypic lesion of the bone," New Horizons in Clinical Case Reports, vol. 2, pp. 1-3.

[26] K. Maatallah, M. Boudokhane, H. Ferjani, D. Kaffel, M. M. Kchir and W. Hamdi, "Calcaneal intraosseous lipoma: A rare cause of heel pain," The Egyptian Rheumatologist, vol. 41, no. 4, pp. 319-321, 2019.

[27] K. Muramatsu, Y. Tominaga, T. Hashimoto and T. Taguchi, "Symptomatic intraosseous lipoma in the calcaneus," Anticancer Res, vol. 34, no. 2, pp. 963-966, 2014.

[28] K. Chowdhary, M. Zaman, G. Kaur, A. Shah, R. Yadav, A. Chowdhary and I. Inkov, "Lipoma over plantar aspect of foot: an uncommon site for a common lump," Int J Med Rev Case Rep, vol. 2, no. 4, pp. 103-104, 2018.

[29] K. Moustaide, S. Gallouj, A. Nassiri and F. Z. Mernissi , "A rare case of plantar lipoma," Journal of Dermatology \& Cosmetology, vol. 2, no. 2, pp. 126-127, 2018.

[30] G. Salti, I. Ghersetich, F. Tantussi, B. Bovani and T. Lotti, “Phosphatidylcholine and Sodium Deoxycholate in the Treatment of Localized Fat: A Double-Blind, Randomized Study," Dermatologic Surgery, vol. 34, no. 1, pp. 60-66, 2008.

[31] S. Nanda, "Treatment of Lipoma by Injection Lipolysis," J Cutan Aesthet Surg, vol. 4, no. 2, pp. 135-137, 2011.

[32] C. Scarpa, V. Vindigni and F. Bassetto, "Extracorporeal Acoustic Wave Therapy and Multiple Symmetric Lipomatosis," Plast Reconstr Surg Glob Open, vol. 3, no. 6, p. e430, 2015.

[33] W. G. Stebbins, C. W. Hanke and J. Petersen, "Novel method of minimally invasive removal of large lipoma after laser lipolysis with 980 nm diode laser," Dermatol Ther, vol. 24, no. 1, pp. 125130, 2011.

[34] A. Shemer, S. Brawer, D. V. Solli, B. Amichi and H. Azhari, "Noninvasive Lipoma Size Reduction Using High-Intensity Focused Ultrasound," Dermatologic Surgery, vol. 39, no. 10, pp. 1446-1451, 2013.

[35] F. Kässner, T. Sauer, M. Penke, S. Richter, K. Landgraf, A. Körner, W. Kiess, N. Händel and A. 
Garten, "Simvastatin induces apoptosis in PTEN-haploinsufficient lipoma cells," International Journal of Molecular Medicine, vol. 41, no. 6, pp. 3691-3698, 2018.

[36] T. H. Lui, "Endoscopic resection of subcutaneous lipoma and tumor-like lesion of the foot," The Foot, vol. 26, pp. 36-40, 2016.

[37] G. Kinoshita, M. Matsumoto, T. Maruoka, T. Shiraki, K. Tsunemi, H. Futani and S. Maruo, "Bone and Soft Tissue Tumours of the Foot: Review of 83 Cases," Journal of Orthopaedic Surgery, vol. 10, no. 2, pp. 173-178, 2002.

[38] C. Errani, F. Traina, F. Perna, C. Calamelli and C. Faldini, "Current concepts in the biopsy of musculoskeletal tumors," The Scientific World Journal, pp. 1-7, 2013.

[39] A. D. Singer, A. Datir, J. Tresley, T. Langley, P. D. Clifford, J. Jose and T. K. Subhawong, "Benign and malignant tumors of the foot and ankle," Skeletal Radiol, vol. 45, no. 3, pp. 287-305, 2016.

[40] N. Harrasser, M. Recker, U. Lenze, F. Pohlig, L. Gerdesmeyer and R. v. Eisenhart-Rothe, "Distribution patterns of foot and ankle tumors: a university tumor institute experience," $B M C$ Cancer, vol. 18, no. 1, 2018.

[41] M. Khoo, I. Pressney, R. Hargunani and A. Saifuddin, "Small, superficial, indeterminate softtissue lesions as suspected sarcomas: is primary excision biopsy suitable?," Skeletal Radiol, vol. 46, pp. 919-924, 2017.

[42] J. Nishio, T. Isayama, I. Yoshimura, H. Ohjimi, H. Iwasaki and M. Naito, "Myxoid Liposarcoma of the Ankle: A Case Report," The Journal of Foot and Ankle Surgery, vol. 51, no. 1, pp. 76-79, 2012.

[43] P. Hughes, R. Miranda and A. J. Doyle, "MRI imaging of soft tissue tumours of the foot and ankle," Insights into Imaging, vol. 10, no. 1, pp. 1-13, 2019.

[44] C. Errani, F. Traina, F. Perna, C. Calamelli and C. Faldini, "Current concepts in the biopsy of musculoskeletal tumors," The Scientific World Journal, 2013.

[45] E. E. Hurwitz, M. Simon, S. R. Vinta, C. F. Zehm, S. M. Shabot, A. Minhajuddin and A. E. Abouleish, "Adding Examples to the ASA-Physical Status Classification Improves Correct Assignment to Patients," Anesthesiology, vol. 126, no. 4, pp. 614-622, 2017.

[46] NICE, "NICE Sarcoma Quality Standard QS78," 29 January 2015. [Online]. Available: https://www.nice.org.uk/guidance/qs78. [Accessed 22 September 2020].

[47] NICE, "NICE Suspected cancer: recognition and referral," 23 June 2015. [Online]. Available: https://www.nice.org.uk/guidance/ng12. [Accessed 22 September 2020].

[48] "East Midlands Sarcoma Service," [Online]. Available: https://www.eastmidlandssarcoma.org.uk/making-a-referral/. [Accessed 20.09.2020 September 2020].

[49] A. Uddin and I. Reilly, "Ropivacaine and levobupivacaine: new drugs for podiatric medicine and surgery," Podiatry Now, pp. 22-28, 2008.

[50] G. Kuthiala and G. Chaudhary, "Ropivacaine: A review of its pharmacology and clinical use," Indian Journal of Anaesthesia, vol. 55, no. 2, pp. 104-110, 2011.

[51] J. Dawson, J. Coffey, H. Doll, G. Lavis, P. Cooke and M. Herron, "A patient based questionnaire to assess outcomes of foot surgery: validation in the context of surgery for hallux valgus," Qual Life Res, vol. 15, no. 7, pp. 1211-1222, 2006.

[52] S. Rammelt, H. Fritzsche, C. Hofbauer and K. D. Schaser, "Malignant tumours of the foot and 
ankle," Foot Ankle Surg, vol. 26, no. 4, 2020.

[53] T. Zeytoonjian, H. J. Mankin, M. C. Gebhardt and F. J. Hornicek, "Distal lower extremity sarcomas: frequency of occurrence and patient survival rate," Foot Ankle Int, vol. 25, no. 5, pp. 325-330, 2004.

[54] L. D. Latt, R. E. Turcotte, M. H. Isler and C. Wong, "Case series. Soft-tissue sarcoma of the foot," Can J Surg, vol. 53, no. 6, pp. 424-431, 2010.

[55] P. H. England, "Cancer Data," [Online]. Available: https://www.cancerdata.nhs.uk/getdataout/sarcoma. [Accessed 22.10.2020 October 2020].

[56] M. G. Hochman and J. S. Wu, "MR Imaging of Common Soft Tissue Masses in the Foot and Ankle," Magn Reson Imaging Clin N Am, vol. 25, no. 1, pp. 159-181, 2017.

[57] G. Rahmani , P. McCarthy and D. Bergin, "The diagnostic accuracy of ultrasonography for soft tissue lipomas: a systematic review," Acta Radiol Open, vol. 6, no. 6, pp. 1-6, 2017.

[58] J. Galant , L. Martí-Bonmatí, F. Sáez, R. Soler, R. Alcalá-Santaella and M. Navarro, "The value of fat-suppressed T2 or STIR sequences in distinguishing lipoma from well-differentiated liposarcoma," Eur Radiol, vol. 13, no. 2, pp. 337-343, 2003.

[59] J. A. Welker, R. M. Henshaw, J. Jelinek, B. M. Shmookler and M. M. Malawer, "The percutaneous needle biopsy is safe and recommended in the diagnosis of musculoskeletal masses," Cancer, vol. 15, no. 89, pp. 2677-2686., 2000.

[60] G. U. Exner, M. O. Kurrer, N. Mamisch-Saupe and S. R. Cannon, "The tactics and technique of musculoskeletal biopsy," EFORT Open Rev, vol. 2, no. 2, pp. 51-57, 2017.

[61] P. Cardoso, J. Rosa, J. Esteves, V. Oliveira and R. Rodrigues-Pinto, "Fine needle aspiration for the diagnosis and treatment of musculoskleletal tumours," Acta Orthopaedica et Traumatologica Turcica, vol. 51, no. 4, pp. 278-283, 2017.

[62] Y. J. Yang and T. A. Damron, "Comparison of needle core biopsy and fine-needle aspiration for diagnostic accuracy in musculoskeletal lesions," Arch Pathol Lab Med, vol. 128, no. 7, pp. 759764, 2004.

[63] S. E. Kilpatrick, J. O. Cappellari, G. D. Bos, S. H. Gold and W. G. Ward, "Is fine-needle aspiration biopsy a practical alternative to open biopsy for the primary diagnosis of sarcoma? Experience with 140 patients," Am J Clin Pathol, vol. 115, no. 1, pp. 59-68, 2001.

[64] A. Toepfer, N. Harrasser, M. Recker, U. Lenze, F. Pohlig, L. Gerdesmeyer and R. von EisenhartRothe, "Distribution patterns of foot and ankle tumors: a university tumor institute experience," BMC Cancer, vol. 18, no. 1, 2018.

[65] N. R. Colterjohn, A. M. Davis, B. O'Sullivan, C. N. Catton and J. S. Wunder, "Functional outcome in limb-salvage surgery for soft tissue tumours of the foot and ankle," Sarcoma, vol. 1, no. 2, pp. 67-74, 1997.

[66] M. J. Parker, V. Livingstone, R. Clifton and A. McKee, "Closed suction surgical wound drainage after orthopaedic surgery," Cochrane Database of Systematic Reviews, 2007.

\section{Figures}




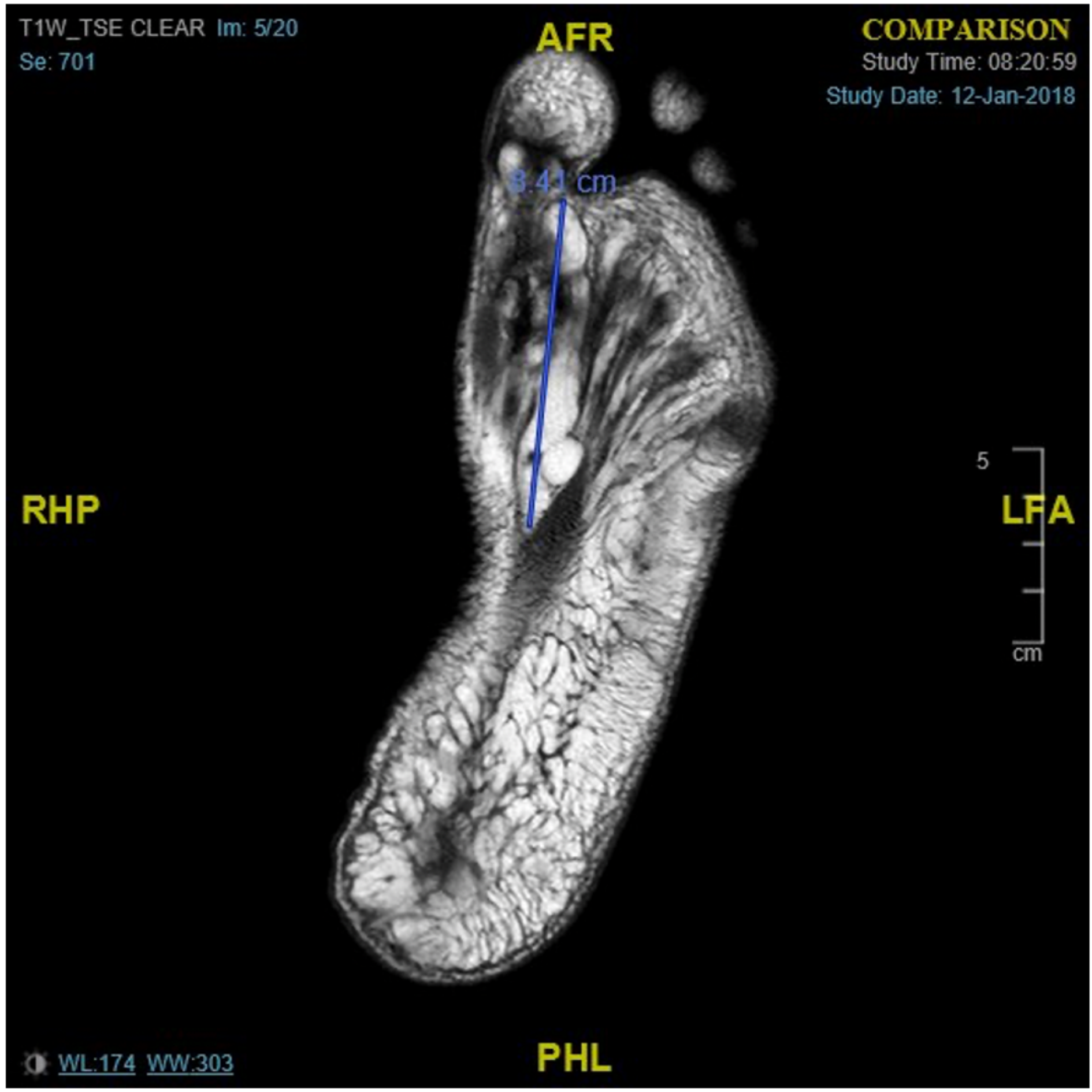

Figure 1

Pre-operative MRI images 


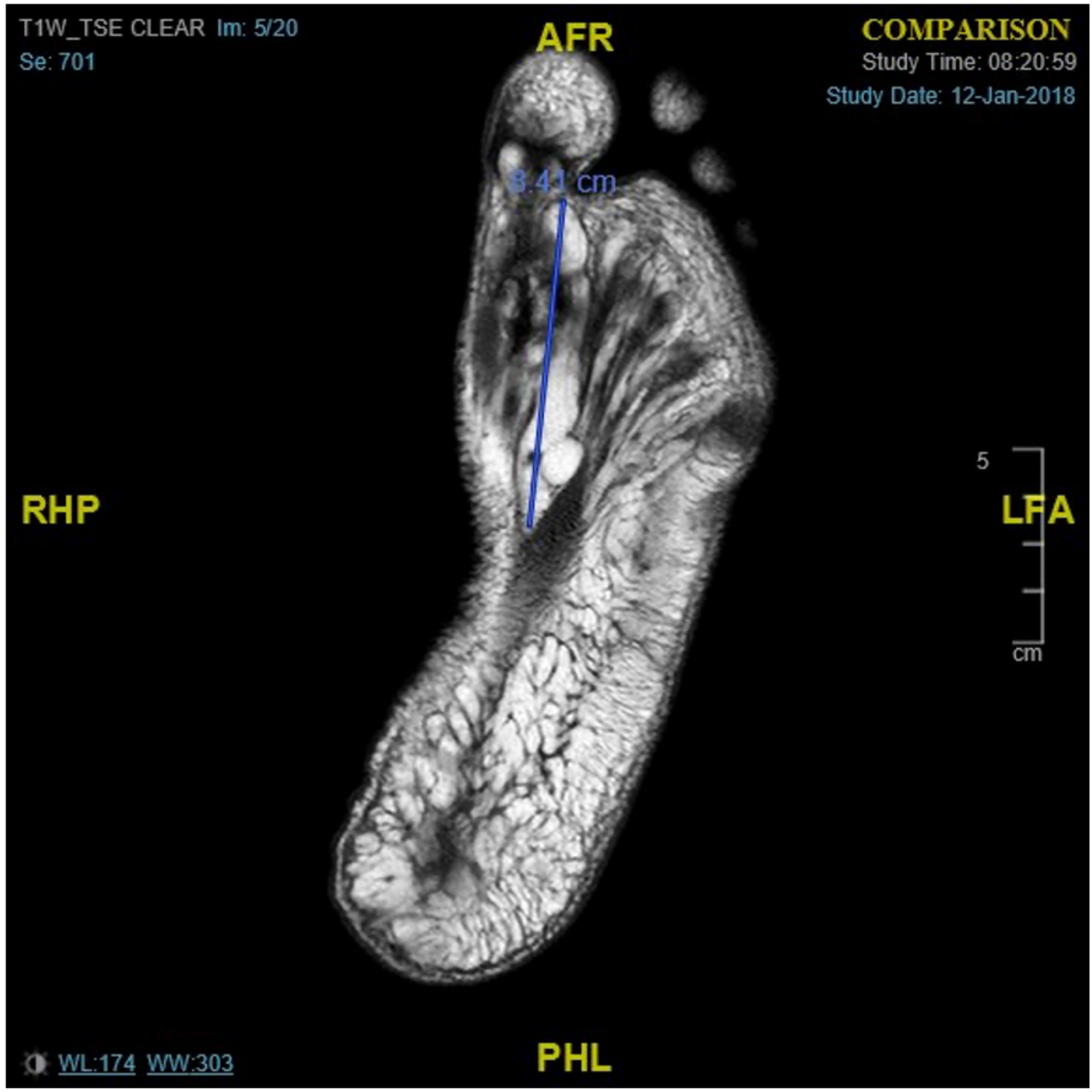

Figure 1

Pre-operative MRI images 
T1W_TSE CLEAR Im: 7/30

Se: 501

\section{COMPARTSON}

Study Time: 08:20:59

Study Date: 12-Jan-2018

\section{RHA}

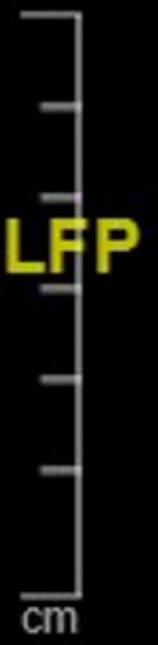

(4. WL:265 WW:461

$$
\text { FRP }
$$

\section{Figure 2}

Pre-operative MRI images 
T1W_TSE CLEAR Im: 7/30

Se: 501

\section{COMPARTSON}

Study Time: 08:20:59

Study Date: 12-Jan-2018

\section{RHA}

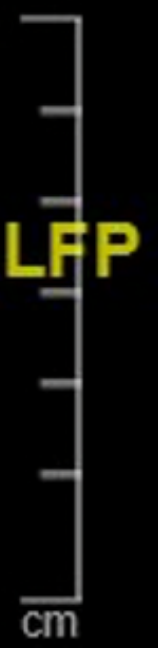

(4) WL:265 WW:461

$$
\text { FRP }
$$

\section{Figure 2}

Pre-operative MRI images 
T1W_TSE CLEAR Im: 13/30

Se: 501

\section{HLA}

COMPARISON Study Time: 08:20:59 Study Date: 12-Jan-2018

RHA

(1) WL:278 WW:484
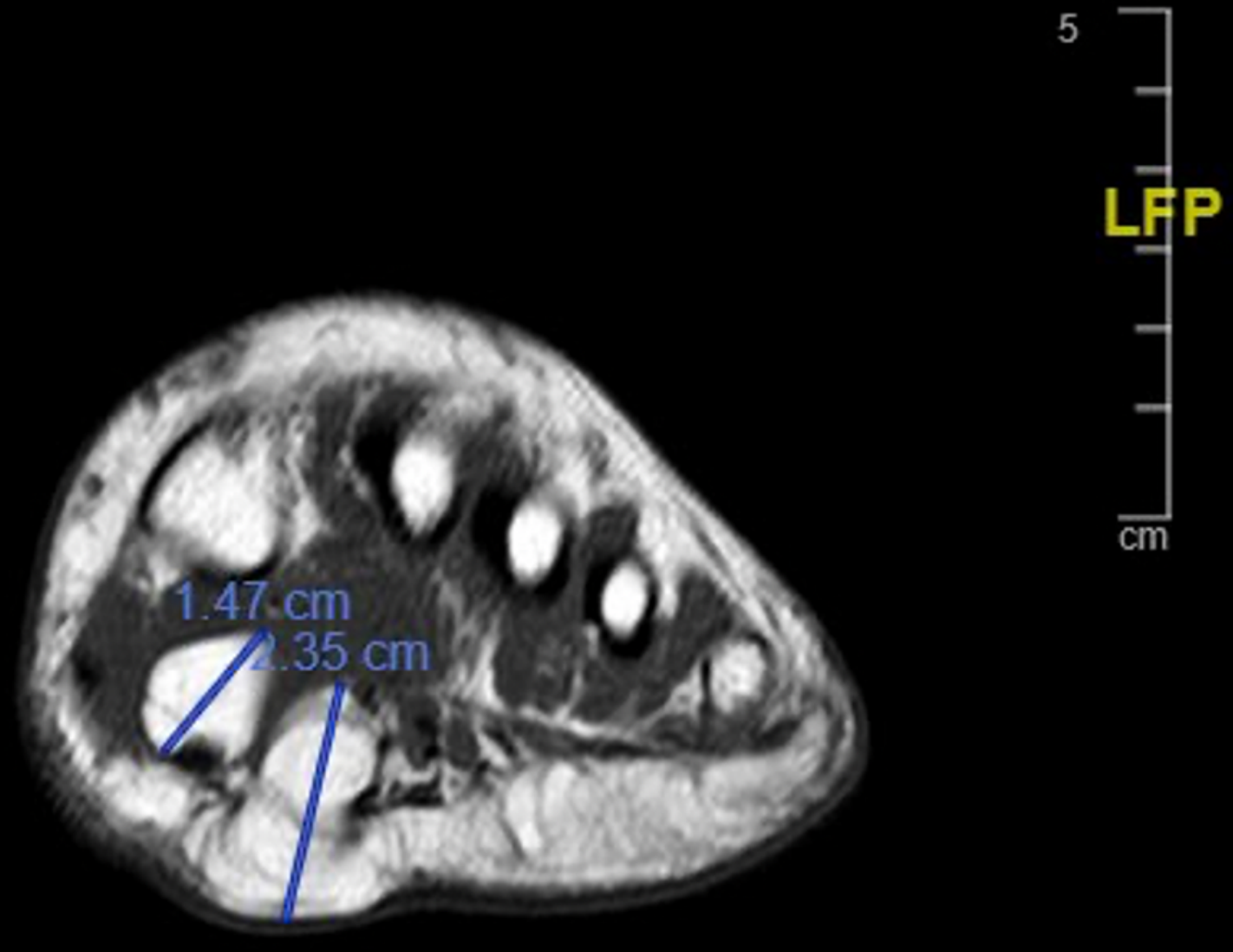

$$
\text { FRP }
$$

\section{Figure 3}

Pre-operative MRI images 
T1W_TSE CLEAR Im: 13/30 Se: 501

HLA

RHA

(1) WL:278 WW:484
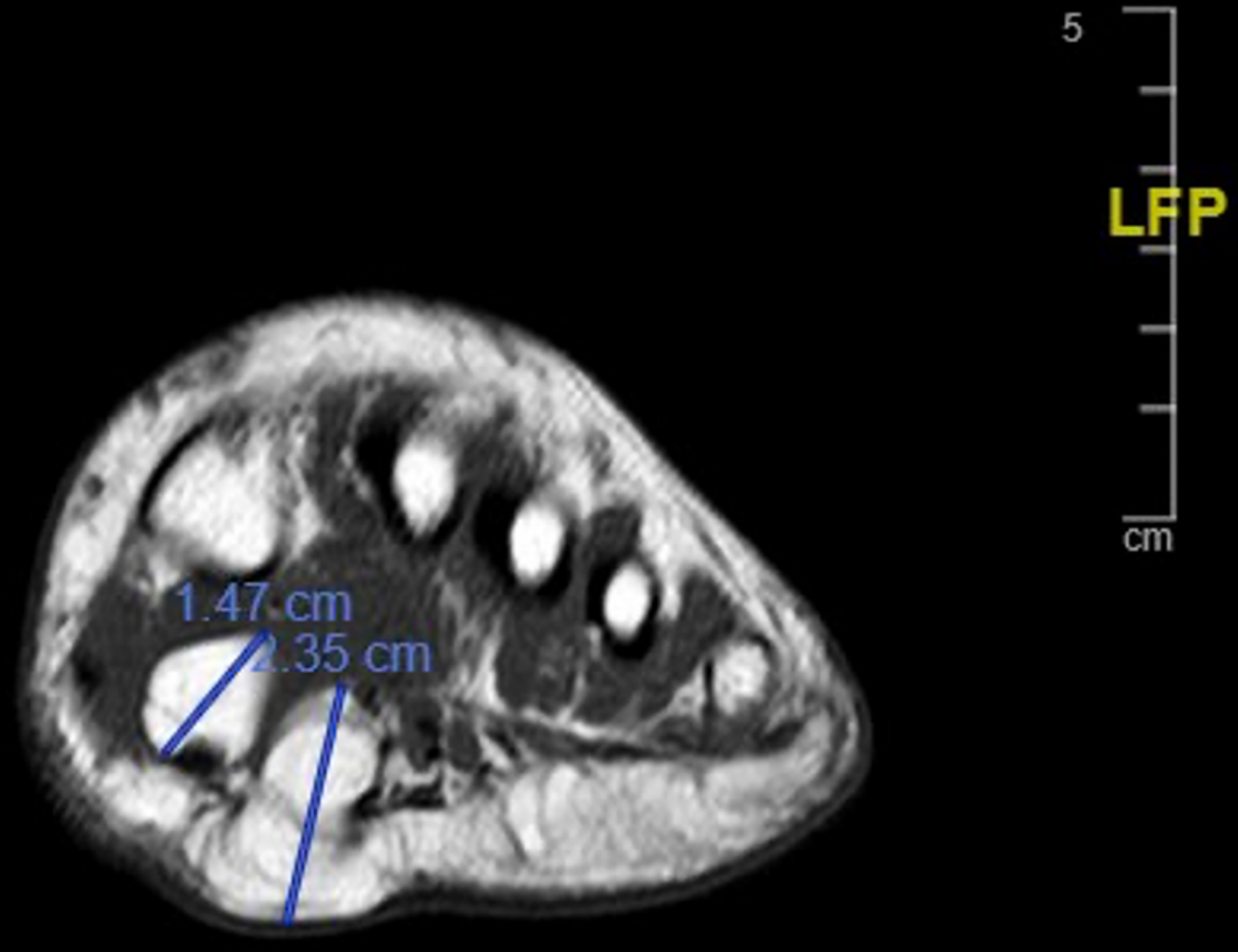

$$
\text { FRP }
$$

COMPARISON Study Time: 08:20:59 Study Date: 12-Jan-2018

\section{Figure 3}

Pre-operative MRI images 


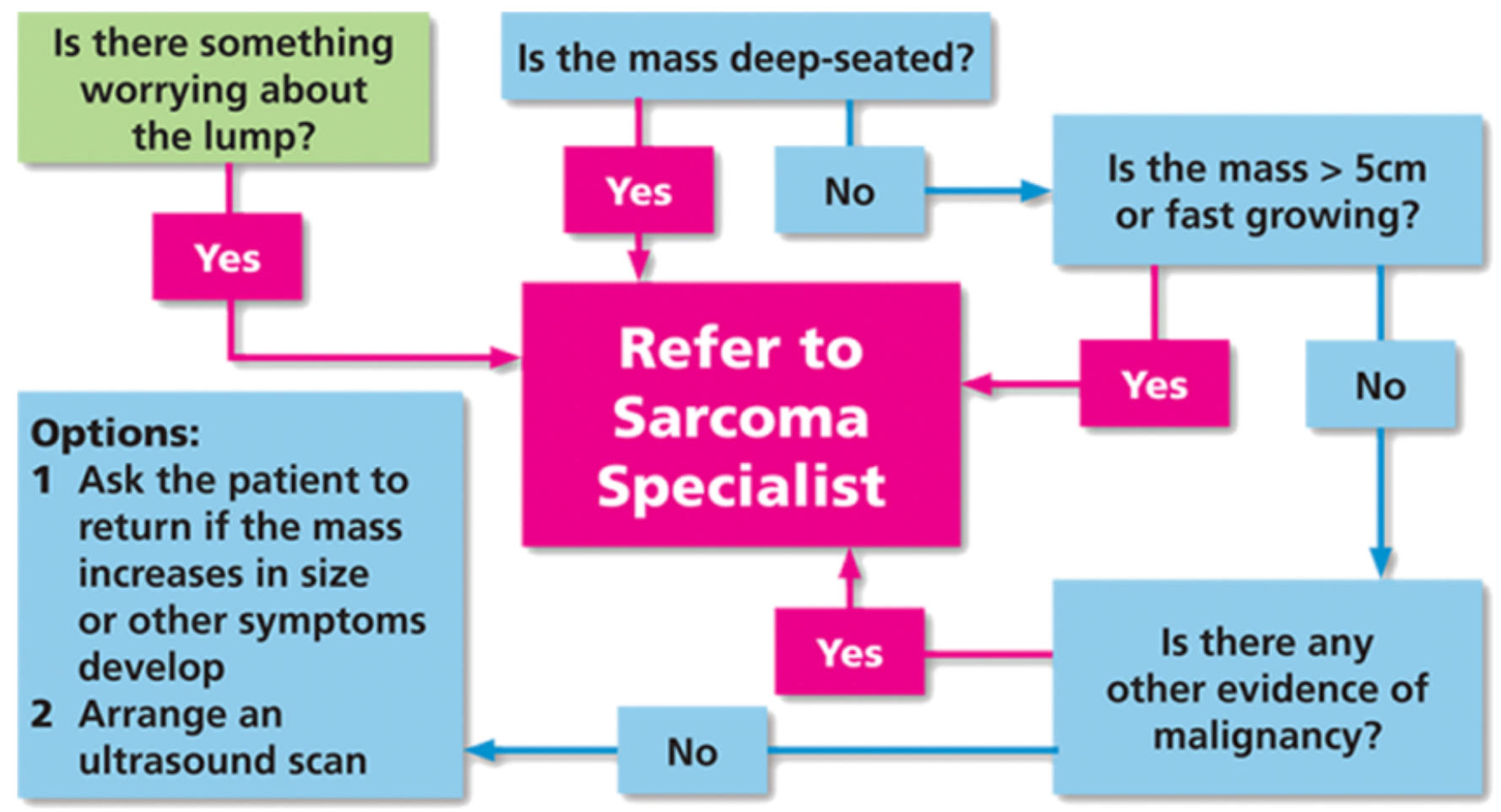

Figure 4

East Midlands Sarcoma Service referral [48].

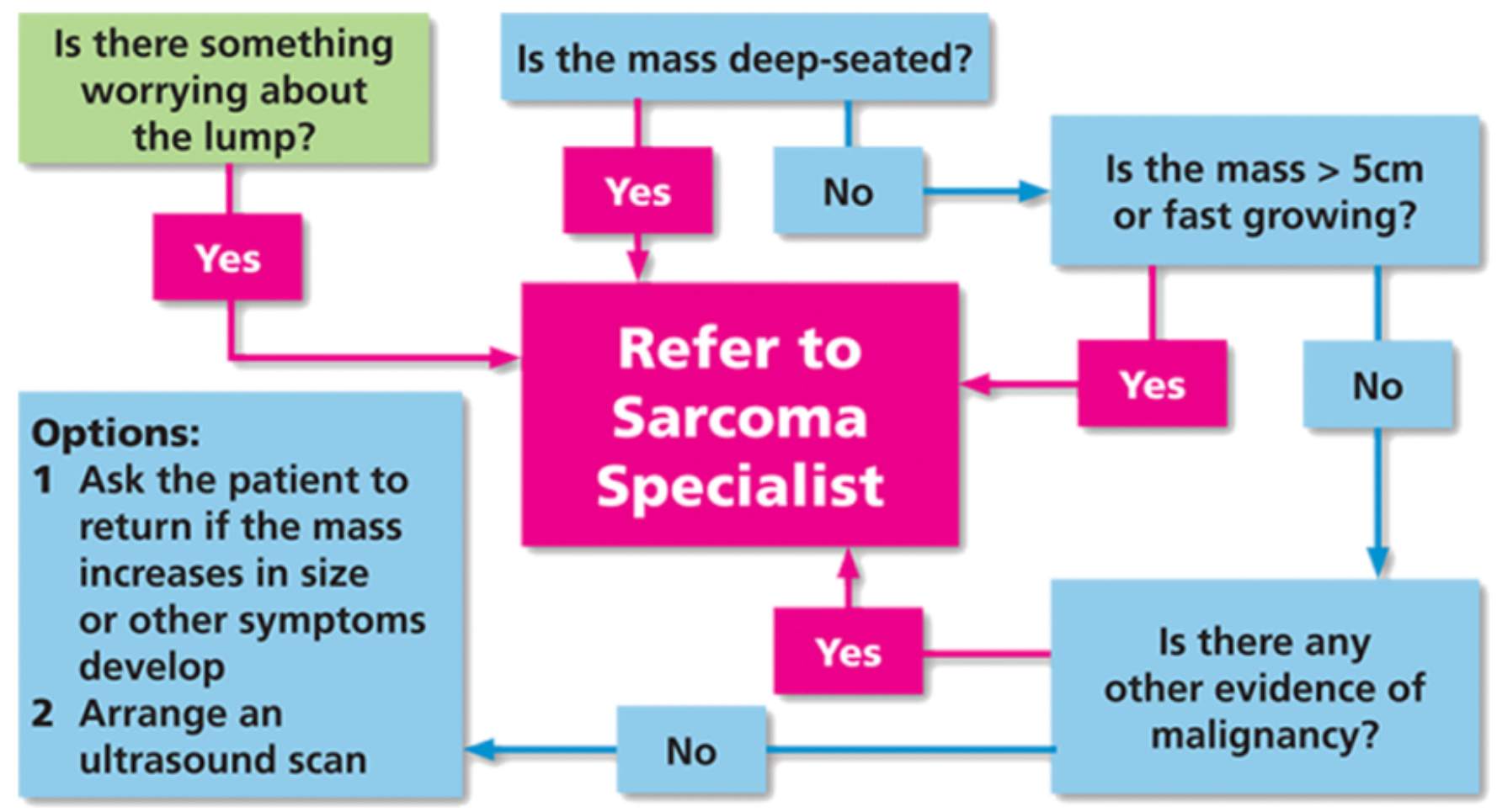

Figure 4 
East Midlands Sarcoma Service referral [48].

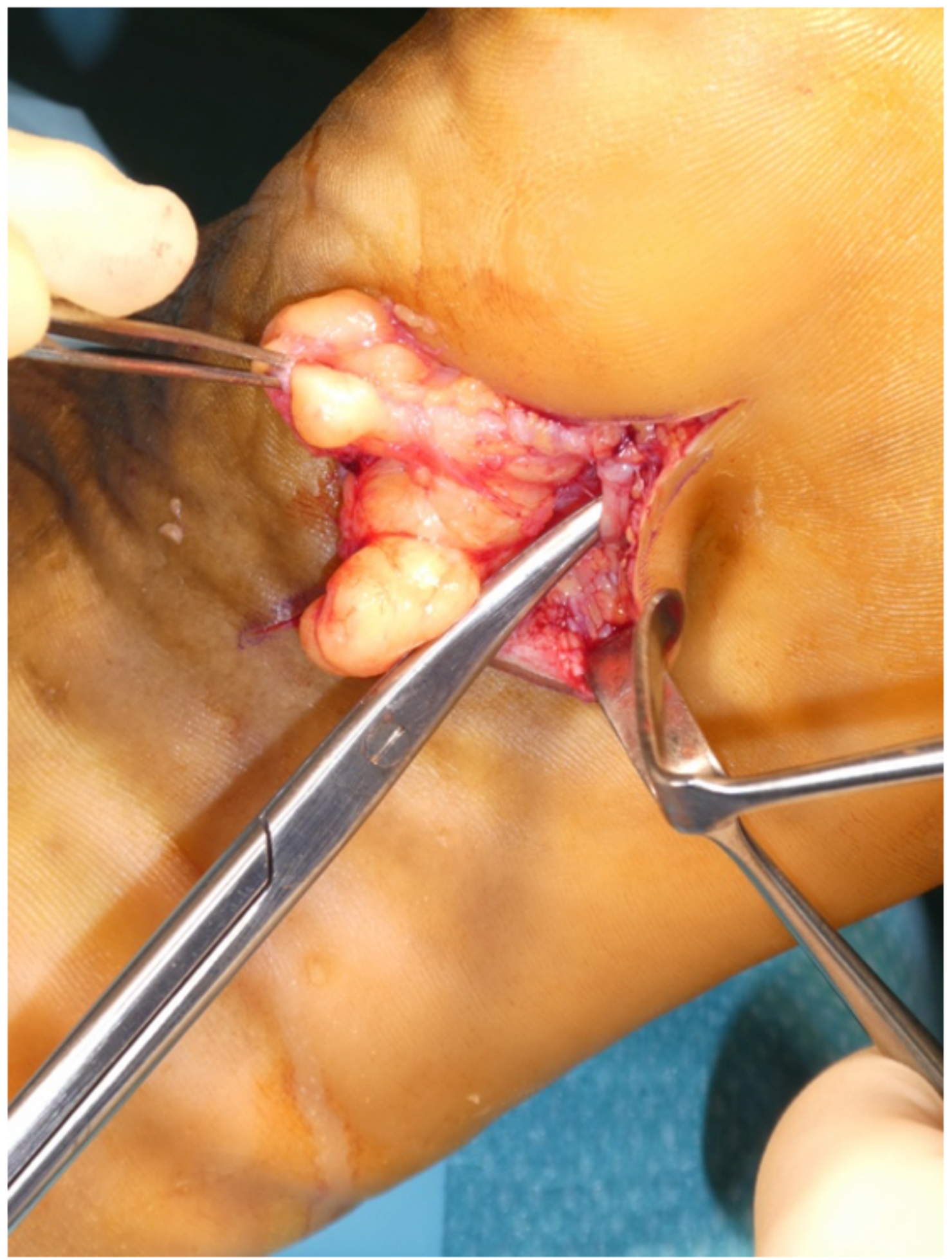

Figure 5

Surgical excision 


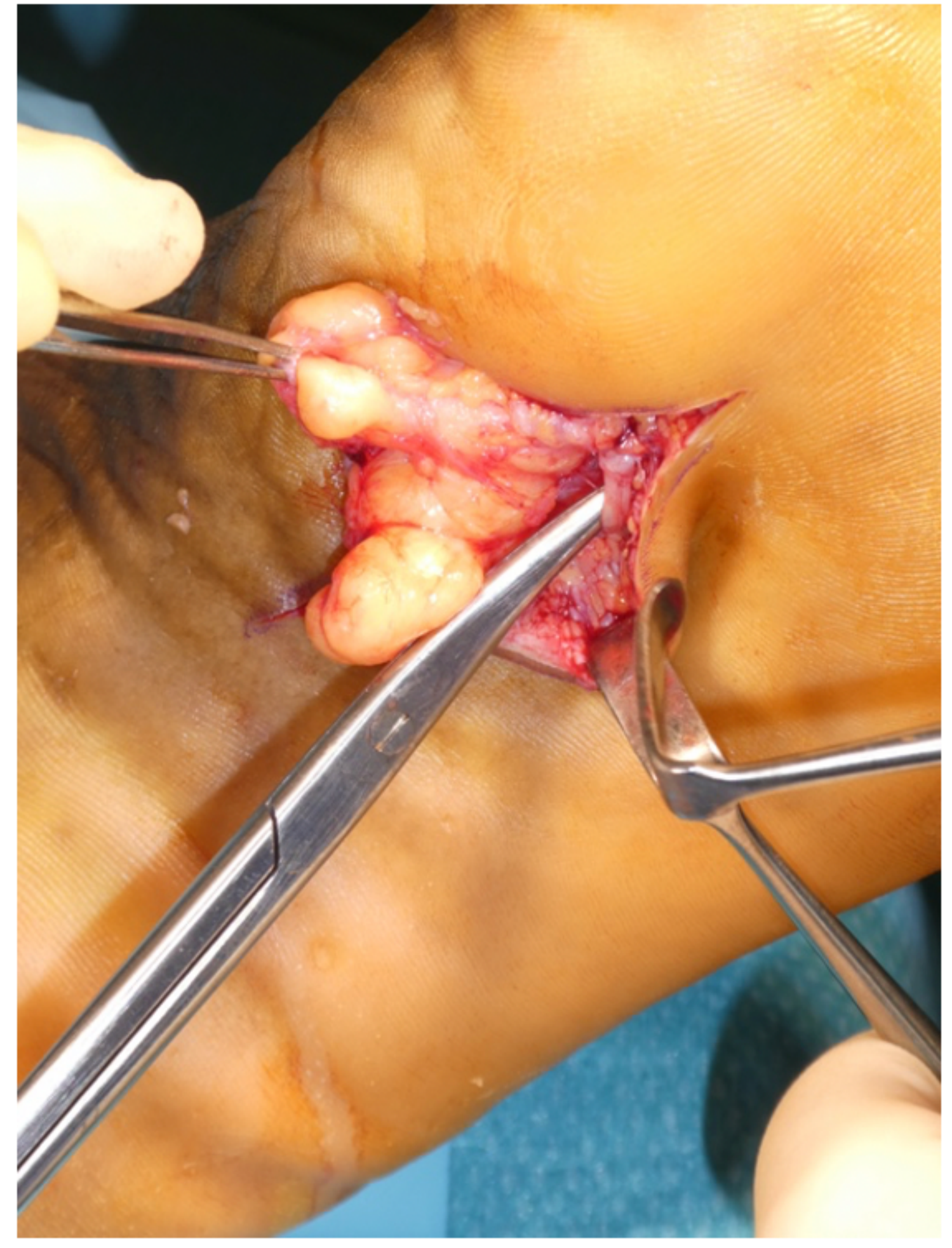

Figure 5

Surgical excision 


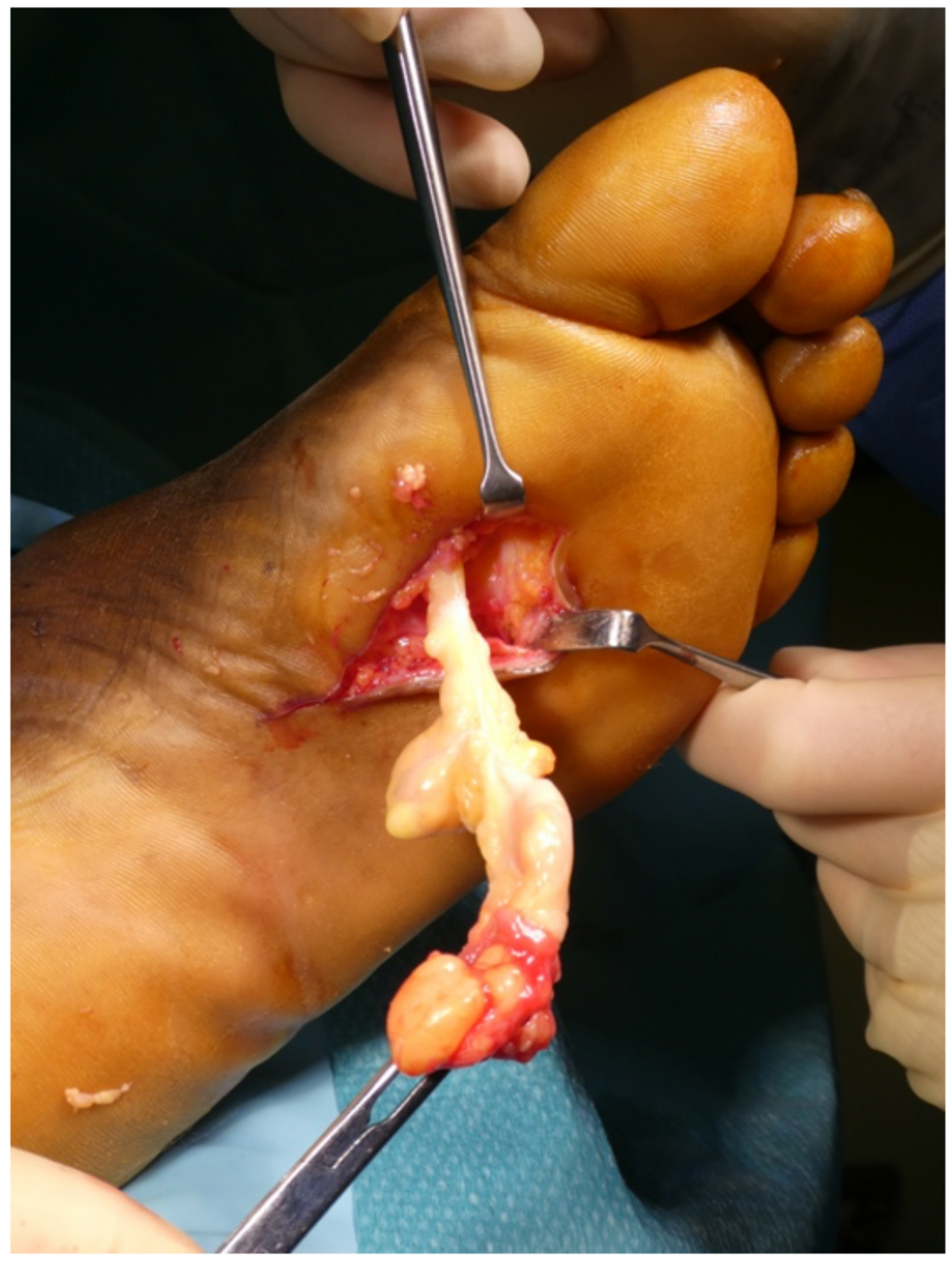

Figure 6

Surgical excision 


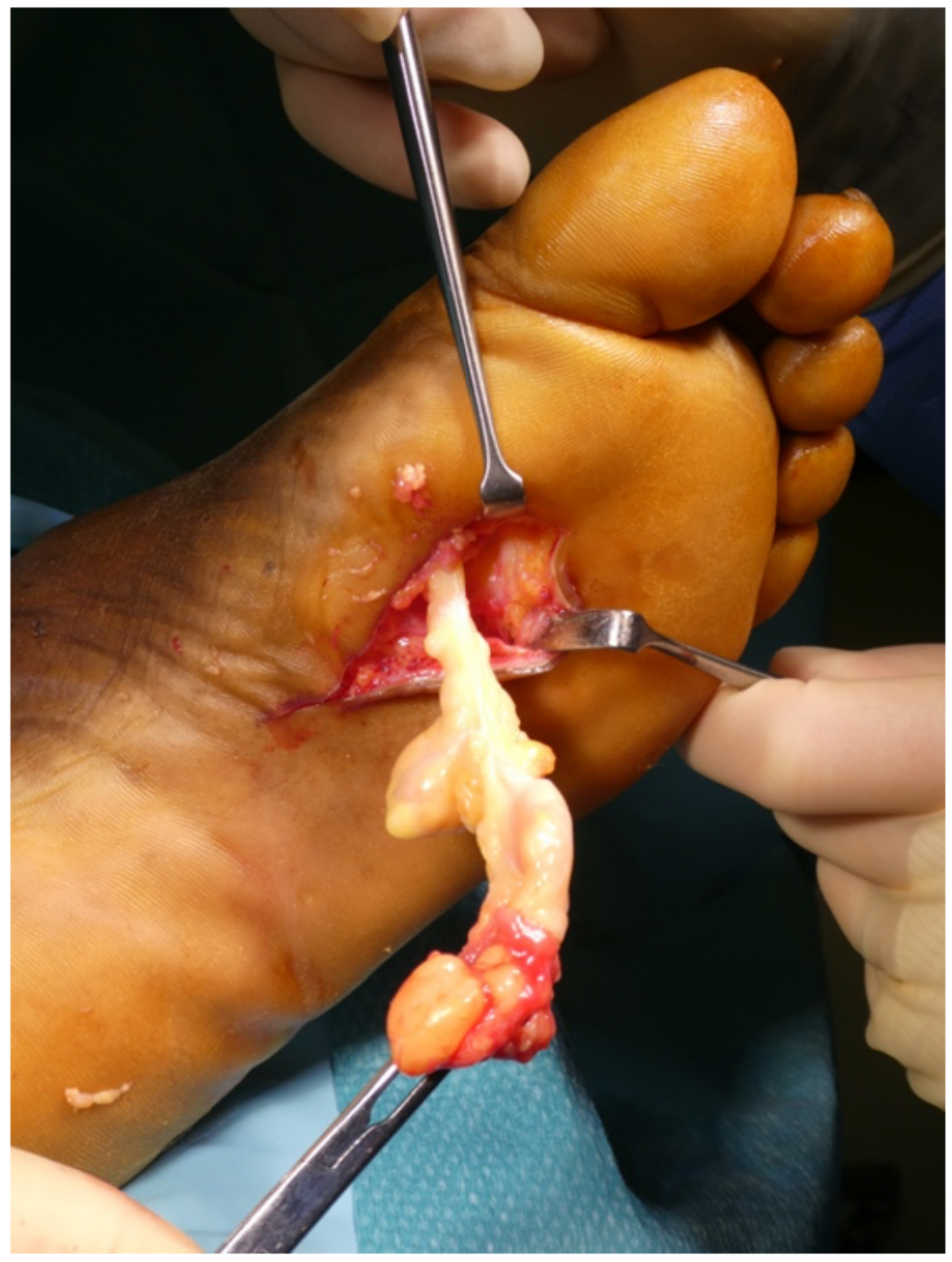

Figure 6

Surgical excision 


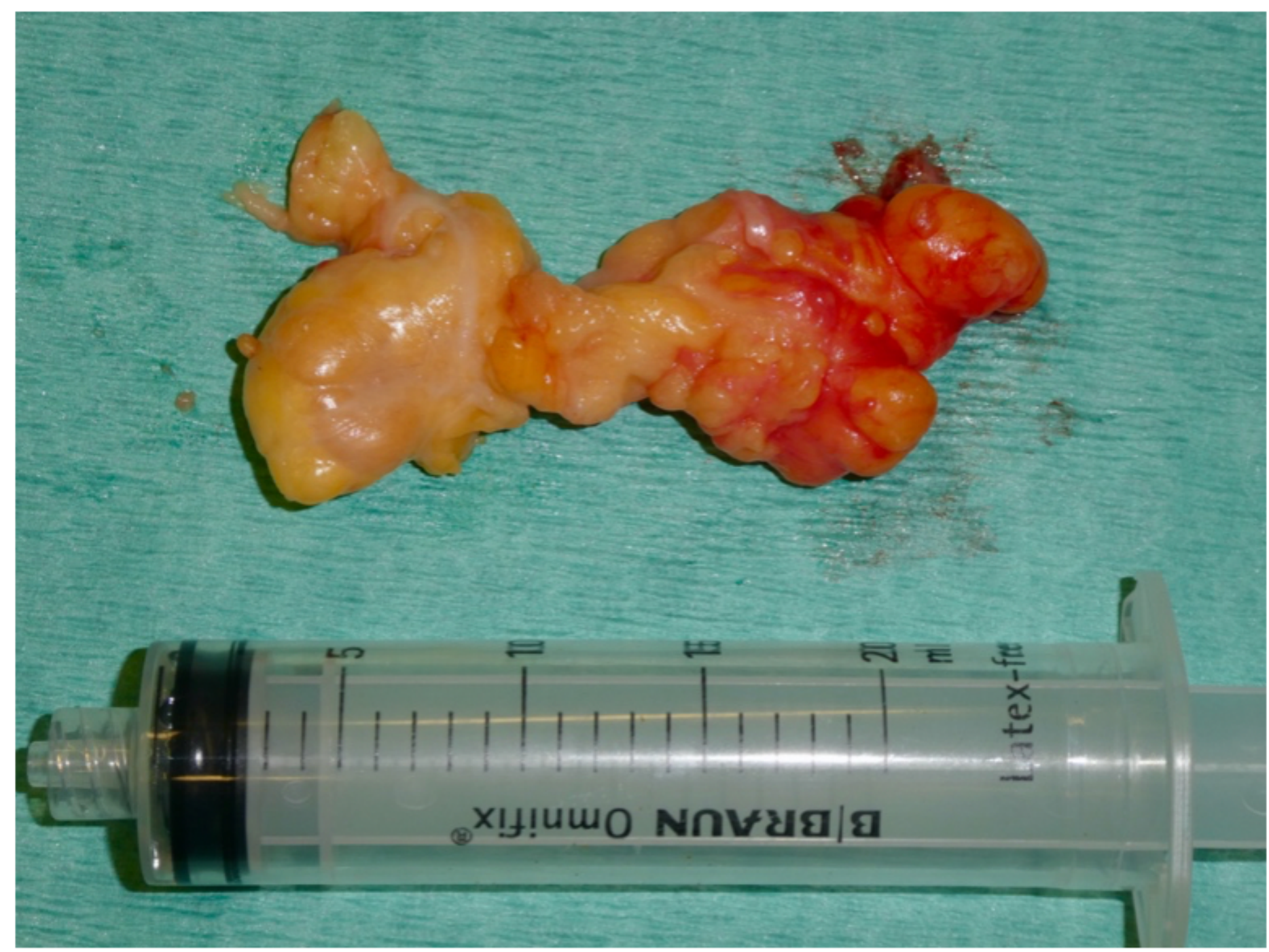

Figure 7

Excised mass, and after closure 


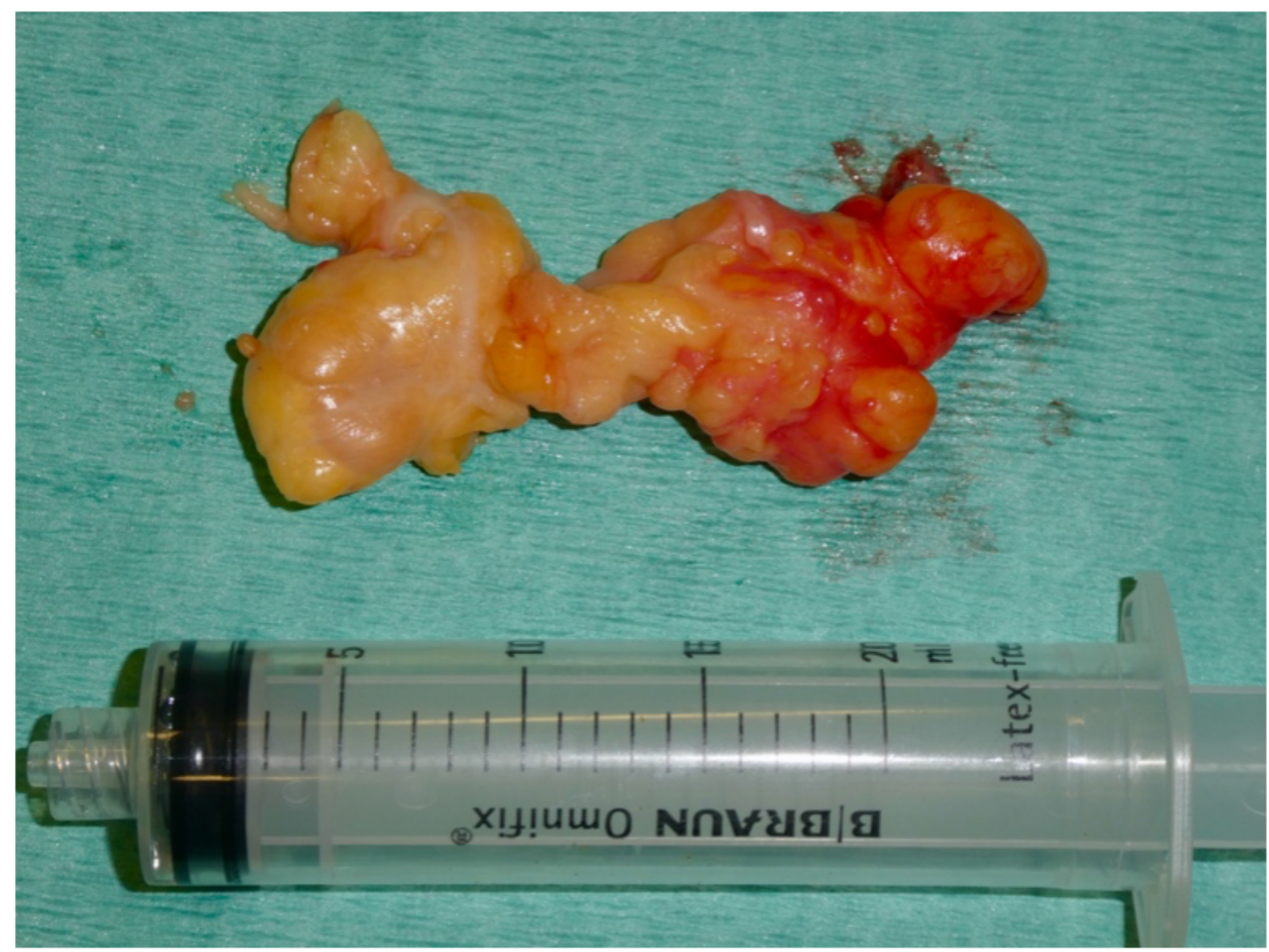

Figure 7

Excised mass, and after closure 


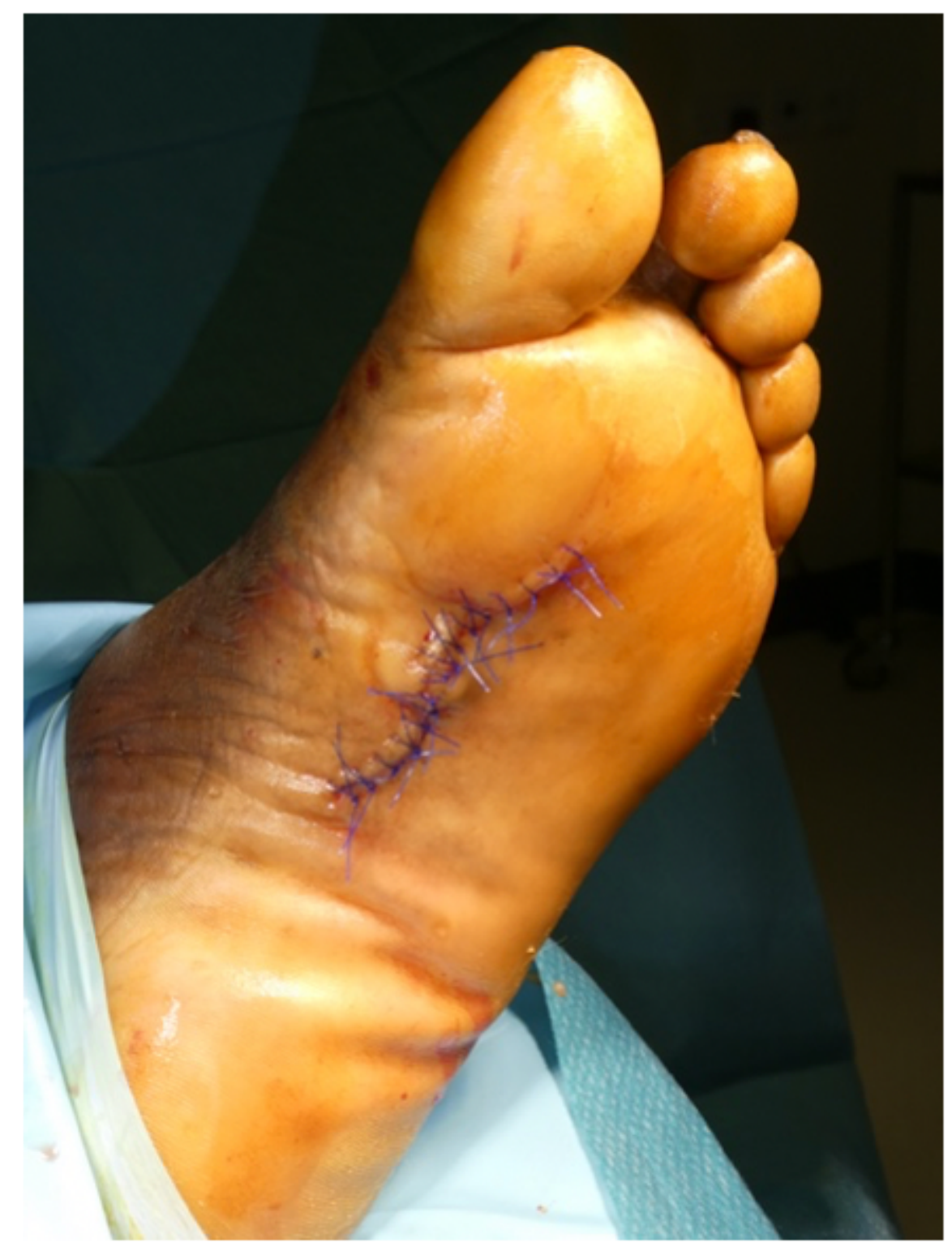

Figure 8

Excised mass, and after closure 


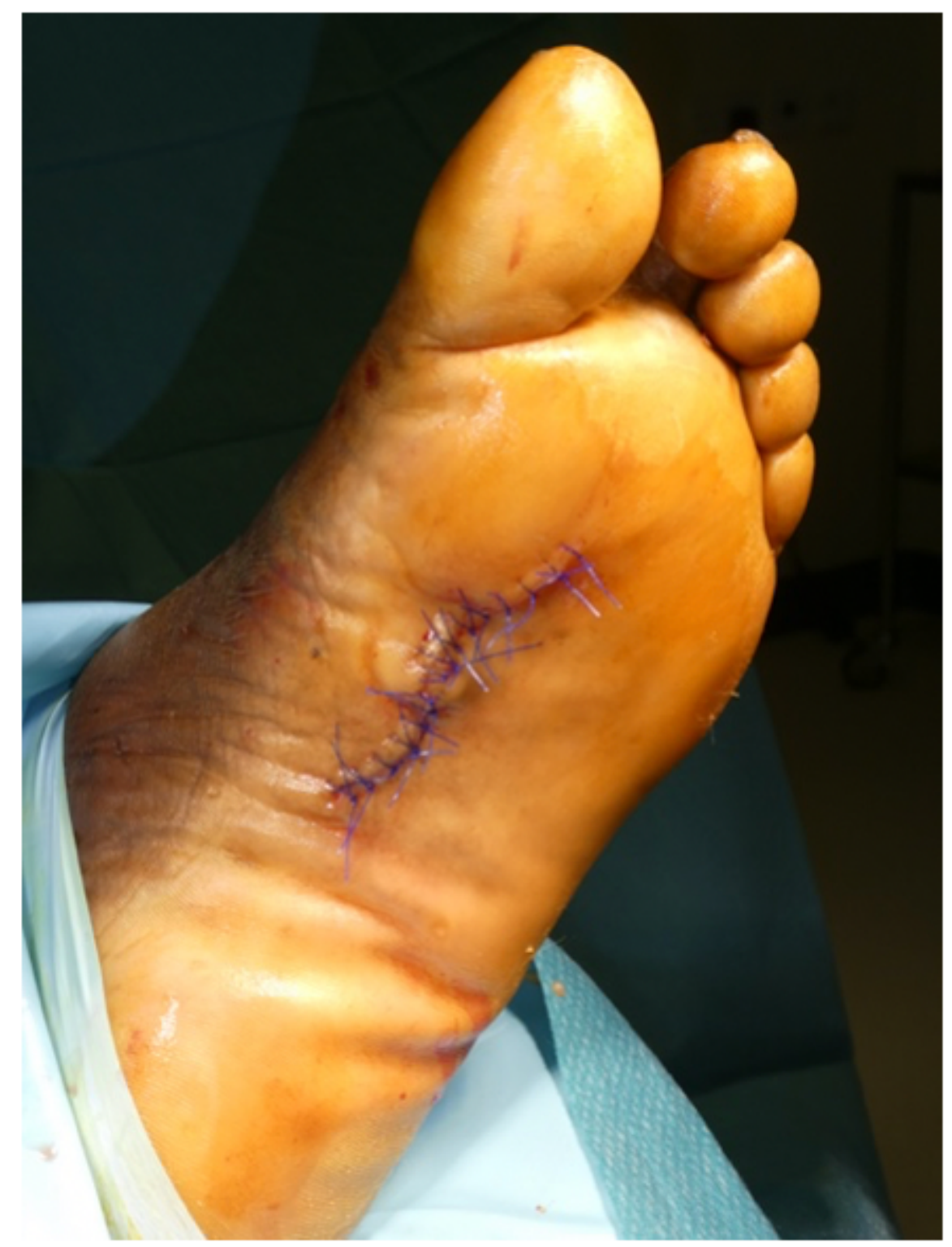

Figure 8

Excised mass, and after closure 


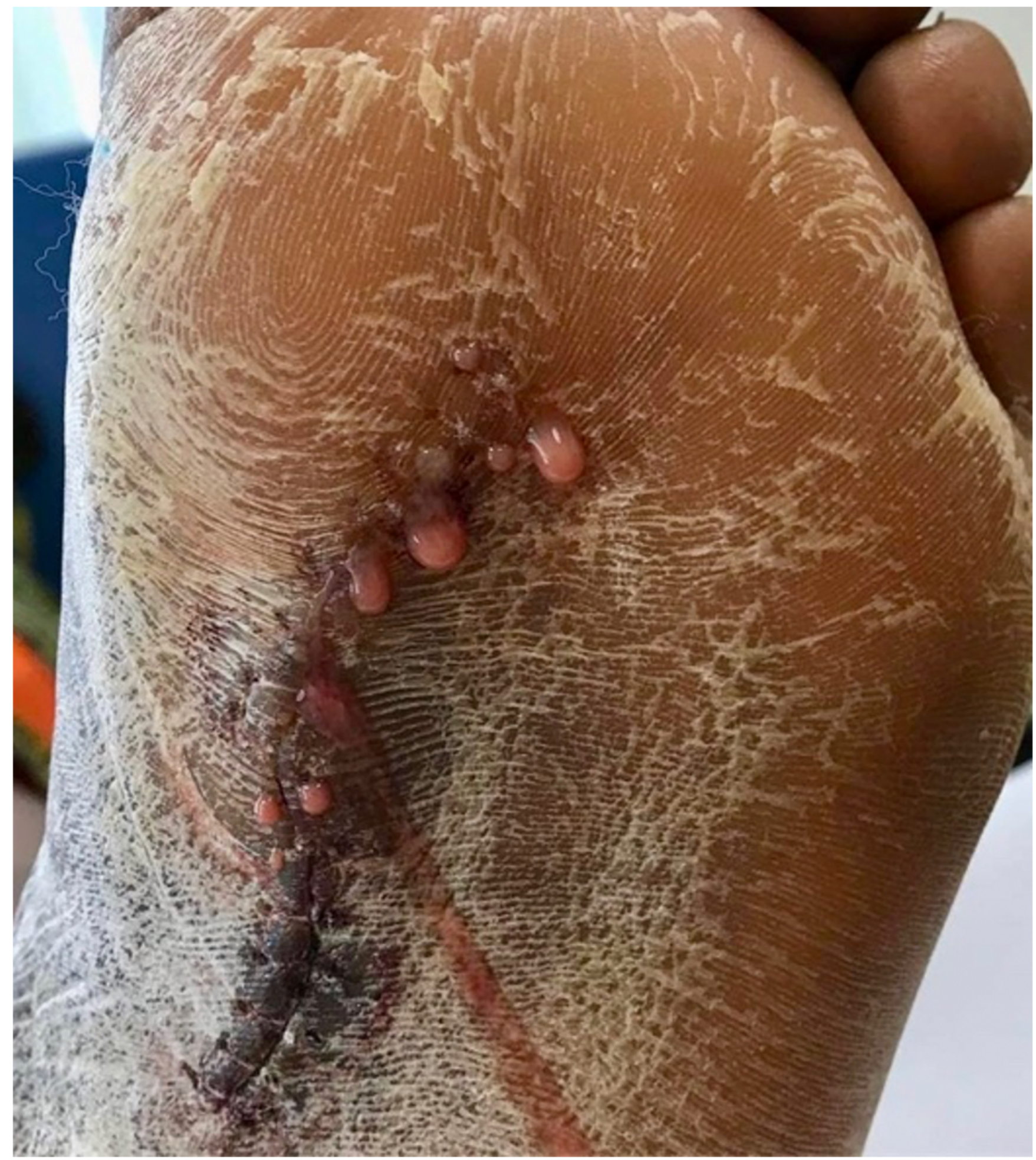

Figure 9

4 weeks post-surgery: aseptic seroma 


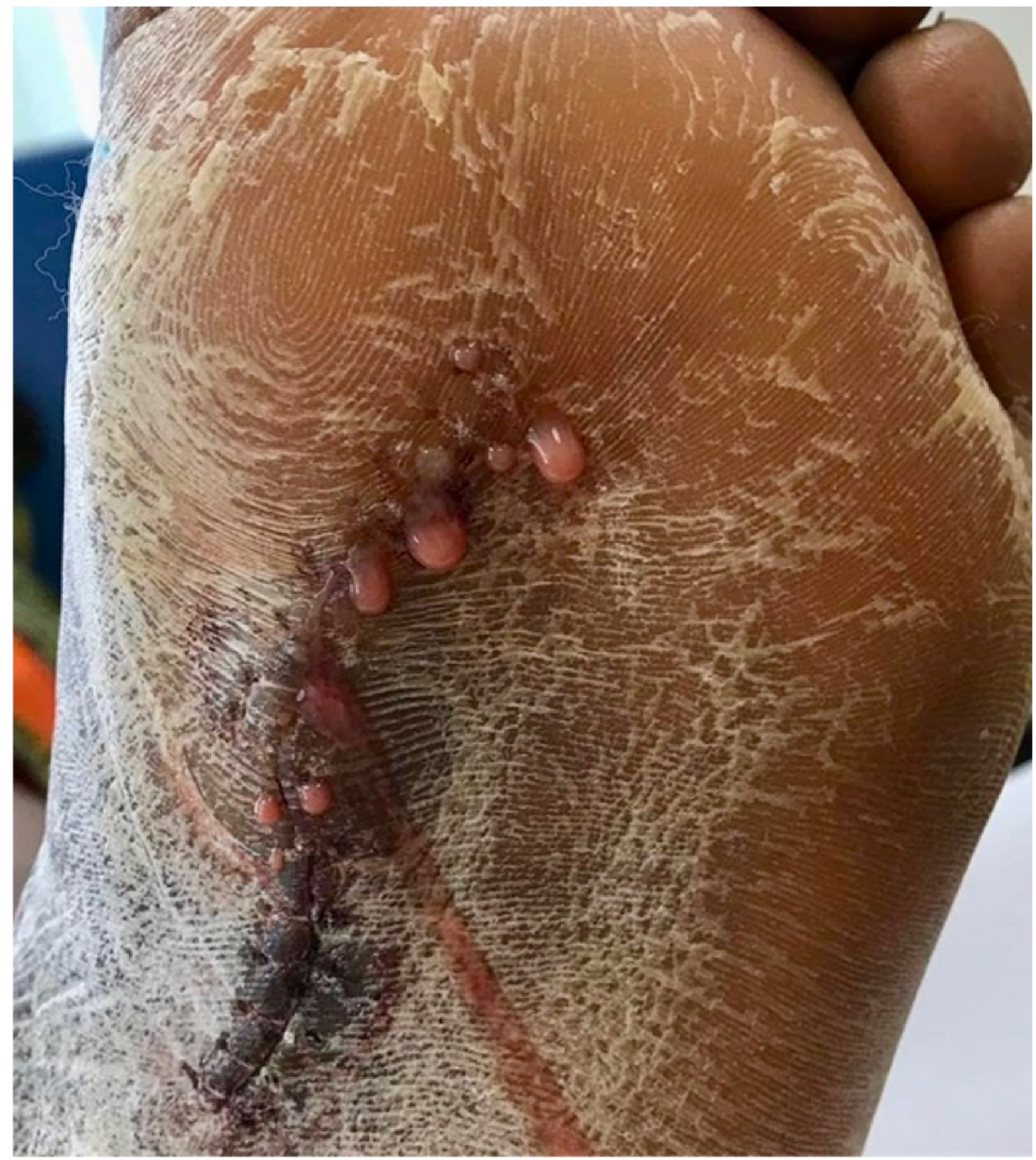

Figure 9

4 weeks post-surgery: aseptic seroma 